\title{
Impacts of External Forcing on the Decadal Climate Variability in CMIP5 Simulations*
}

\author{
YI SONG \\ State Key Laboratory of Numerical Modeling for Atmospheric Sciences and Geophysical Fluid Dynamics, Institute of \\ Atmospheric Physics, Chinese Academy of Sciences, and College of Earth Science, University of the \\ Chinese Academy of Sciences, Beijing, China \\ YONGQIANG YU \\ State Key Laboratory of Numerical Modeling for Atmospheric Sciences and Geophysical Fluid Dynamics, Institute \\ of Atmospheric Physics, Chinese Academy of Sciences, Beijing, China
}

(Manuscript received 16 July 2014, in final form 17 February 2015)

\begin{abstract}
Decadal climate variability is usually regarded as an internal variability in the climate system. However, using the coupled simulations from phase 5 of the Coupled Model Intercomparison Project (CMIP5), it is demonstrated that the external radiative forcing plays an important role in modulating decadal variability of the global mean surface air temperature (SAT). In historical runs, the standard deviations of the global mean SAT exhibit robust increases relative to preindustrial runs, indicating that external forcing acts on decadal variability of the global mean SAT through enhancing amplitude and modulating phase. By comparing model results using different external forcing agents, it is found that the natural forcing agent has the strongest impact on the decadal time scale. Every type of simulation (i.e., the preindustrial, historical, natural forcing, and anthropogenic forcing runs) from almost all the CMIP5 models exhibits a high correlation between the net shortwave (SW) radiative flux at the top of the atmosphere (TOA) and the global mean SAT with a 13-month lag. However, after taking the multimodel ensemble mean for the TOA SW radiative flux and the SAT, respectively, the correlations from the external forcing runs are much higher than those from preindustrial runs. This is because that the decadal SAT anomalies from multiple models cancel each other out in the preindustrial runs without external forcing but generally follow decadal evolution of the external forcing with a 13-month lag. The most significant regional responses to external forcing are found in the tropical Indian and Pacific Oceans, although with different physical mechanisms for the natural and greenhouse gas forcing agents.
\end{abstract}

\section{Introduction}

Both atmospheric and oceanic circulations exhibit prominent fluctuations on decadal and multidecadal time scales. Despite rising concentrations of atmospheric greenhouse gases (GHGs), the global mean surface air temperature (SAT) has remained flat for the past 16 years (i.e., the recent warming hiatus; Easterling and Wehner 2009). This observation challenges the prevailing view that anthropogenic forcing leads to global warming. An

\footnotetext{
* Supplemental information related to this paper is available at the Journals Online website: http://dx.doi.org/10.1175/JCLI-D-14-00492.s1.

Corresponding author address: Yongqiang Yu, LASG, Institute of Atmospheric Physics, Chinese Academy of Sciences, P.O. Box 9804, Beijing 100029, China.

E-mail: yyq@lasg.iap.ac.cn
}

interpretation regarding the hiatus is the combined effects of internally generated decadal variability [e.g., the negative phase of the interdecadal Pacific oscillation (IPO) or the Atlantic multidecadal oscillation (AMO)] and warming from increasing GHGs (Meehl et al. 2011, 2013; Kosaka and Xie 2013; Tung and Zhou 2013; England et al. 2014; McGregor et al. 2014; Song et al. 2014). The recent warming hiatus might also be due to the negative radiative forcing trends from both volcanic aerosols (Santer et al. 2014, 2015) and the low solar minimum (Hansen et al. 2011). Therefore, both internal variability and external forcing should be considered in near-term climate predictions (Meehl and Teng 2012, 2014; Guemas et al. 2013).

The causes and mechanisms of low-frequency climate variability are not fully understood. Many previous studies have suggested that the interaction among subcomponents of the climate system is the main cause of 
the decadal variability of surface temperature (e.g., large-scale ocean-atmosphere feedbacks). The IPO for the whole Pacific basin sea surface temperature (SST) (Power et al. 1999) or the Pacific decadal oscillation (PDO) for the North Pacific part of the IPO (Mantua et al.1997) has been described as an internally generated decadal ENSO-like pattern or as a low-frequency aspect of ENSO (Jin 1997) resulting from the air-sea interaction of the climate system. The North Atlantic Oscillation (NAO) could cause the multidecadal variability of SAT in the Northern Hemisphere (Delworth et al. 1993; Visbeck et al. 1998; Delworth and Greatbatch 2000; Eden and Jung 2001; Li et al. 2013).

Most previous research has concentrated on investigating the intrinsic factors in the ocean-atmosphere system on the decadal time scale. However, natural and anthropogenic forcing factors also have the potential to influence the decadal variability of SAT. Observational and model-based studies have indicated that natural forcing (e.g., large low-latitude volcanic eruptions and solar insolation changes) could modulate the phases of the Atlantic multidecadal variability and North Pacific decadal variability (Shindell et al. 2001; Otterå et al. 2010; Ineson et al. 2011; Wang et al. 2012). The mid1970s climate shift (Trenberth and Hurrell 1994) has been associated with the increasing GHG concentrations and also an internally generated transition of the IPO (Meehl et al. 2009; Meehl and Arblaster 2011). Identifying the relative roles of internal variability and external forcing in driving decadal variability is therefore a key issue. The coupled simulations (including the preindustrial, historical, and natural- and anthropogenic-forcing runs) from phase 5 of the Coupled Model Intercomparison Project (CMIP5) provide the basic data for answering this question.

When analyzing numerical experiments such as the CMIP and the Atmospheric Model Intercomparison Project (AMIP) simulations, the multimodel ensemble mean (MEM) approach has been widely applied. One MEM approach is used before conducting other statistical analyses, aiming to separate the forced climate variability from internal variability (Lambert and Boer 2001; Gillett et al. 2002), and as such is termed the beforehand multimodel ensemble mean (BMEM) in this study. Another MEM approach is to first use other statistical analyses for each model individually and then average the results from all the models: this measure is referred to as the afterward multimodel ensemble mean (AMEM) and has been widely used to evaluate the performance of CMIP models in predicting ENSO intensities ( Kim and Yu 2012; Bellenger et al. 2014; Langenbrunner and Neelin 2013). More details of these two approaches are described in section 2. Differing from most of previous analyses, it is the first study to compare these two MEM approaches and aims to identify the relative roles of internally generated and externally forced climate variability on a decadal time scale. Meanwhile, through comparing four groups of CMIP5 simulations, the influences of different external forcing agents on decadal variability of SAT can be detected. Not only focusing on the recent warming hiatus, we also make a comprehensive analysis for the all hiatus decades in the twentieth century to present the general mechanism of decadal variability of SAT. The data, models, and methods used in this paper are presented in section 2 . The enhanced SAT decadal variability induced by external forcing and significant lead-lag correlations are analyzed in section 3. The contributions of SST in different ocean basins to global mean SAT are also included in section 3 . Finally, conclusions and a discussion are presented in section 4.

\section{Methods}

\section{a. CMIP5 model datasets}

We analyzed four groups of simulations in the CMIP5 archives (see Table 1). (i) PiControl simulations (labeled CTL; 39 models) were long-time runs with preindustrial (1850) forcings that did not change from year to year; these simulations provided information on internal climate variability. (ii) Historical simulations (i.e., all forcing; 21 models) were forced by both natural (e.g., solar irradiation variations and volcanic aerosols) and anthropogenic forcings (e.g., well-mixed greenhouse gases, ozone, and anthropogenic aerosols). (iii) The historicalGHG simulations (i.e., GHG forcing; 16 models) were the same as the historical simulations except that they were only forced by well-mixed GHG changes. Finally, (iv) the historicalNat simulations (i.e., natural forcing; 16 models) were the same as the historicalGHG simulations except that they were forced by natural variations only. For consistency, when comparing the CTL runs to the others, the first 156 years of each model's CTL run were used. For the forcing of the historical experiments, the major external forcings-solar, greenhouse gas, and land use-are standardized based on the most recent observational databases; the exception is volcanic forcing, for which there is no recommended treatment (Driscoll et al. 2012; Flato et al. 2014). For volcanic forcing, CMIP5 models typically employ one of two prescribed volcanic aerosol datasets: that of Sato et al. (1993) or Ammann et al. (2003). Only one ensemble member of every model was used. This study focused on the decadal variability of oceanic and atmospheric variables; thus, a 720-yr bandpass filter was applied as preprocessing for the 
TABLE 1. CMIP5 models for four groups of simulations adopted in this analysis (Yes indicates experiments included). (Expansions of model name acronyms are available online at http://www.ametsoc.org/PubsAcronymList.)

\begin{tabular}{|c|c|c|c|c|}
\hline Model & PiControl & Historical & HistoricalNat & HistoricalGHG \\
\hline ACCESS1.0 & Yes & & & \\
\hline ACCESS1.3 & Yes & & & \\
\hline BCC_CSM1.1 & Yes & Yes & Yes & Yes \\
\hline BCC_CSM1.1(m) & Yes & & & \\
\hline BNU-ESM & Yes & Yes & Yes & Yes \\
\hline CanESM2 & Yes & Yes & Yes & Yes \\
\hline CCSM4 & Yes & Yes & Yes & Yes \\
\hline CESM1(BGC) & Yes & & & \\
\hline CESM1(CAM5) & Yes & & & \\
\hline CESM1(FASTCHEM) & Yes & & & \\
\hline CESM1(WACCM) & Yes & & & \\
\hline CMCC-CM & Yes & & & \\
\hline CNRM-CM5 & Yes & Yes & Yes & Yes \\
\hline CNRM-CM5.2 & Yes & & & \\
\hline CSIRO Mk3.6.0 & Yes & Yes & Yes & Yes \\
\hline FGOALS-s2 & Yes & Yes & & \\
\hline FIO-ESM & Yes & & & \\
\hline GFDL CM3 & Yes & Yes & Yes & Yes \\
\hline GFDL-ESM2G & Yes & Yes & & \\
\hline GFDL-ESM2M & Yes & Yes & Yes & Yes \\
\hline GISS-E2-H & Yes & Yes & Yes & Yes \\
\hline GISS-E2-H-CC & Yes & & & \\
\hline GISS-E2-R & Yes & Yes & Yes & Yes \\
\hline GISS-E2-R-CC & Yes & & & \\
\hline HadCM3 & & Yes & & \\
\hline HadGEM2-CC & Yes & Yes & & \\
\hline HadGEM2-ES & Yes & Yes & Yes & Yes \\
\hline INM CM4.0 & Yes & & & \\
\hline IPSL-CM5A-LR & Yes & Yes & Yes & Yes \\
\hline IPSL-CM5A-MR & Yes & & & \\
\hline IPSL-CM5B-LR & Yes & & & \\
\hline MIROC-ESM & Yes & Yes & Yes & Yes \\
\hline MIROC-ESM-CHEM & Yes & Yes & Yes & Yes \\
\hline MIROC5 & Yes & & & \\
\hline MPI-ESM-LR & Yes & Yes & & \\
\hline MPI-ESM-MR & Yes & & & \\
\hline MPI-ESM-P & Yes & & & \\
\hline MRI-CGCM3 & Yes & Yes & Yes & Yes \\
\hline NorESM1-M & Yes & Yes & Yes & Yes \\
\hline NorESM1-ME & Yes & & & \\
\hline Total & 39 & 21 & 16 & 16 \\
\hline
\end{tabular}

original model output. A Student's $t$ test with the effective sample sizes (Bretherton et al. 1999) was used.

\section{b. Multimodel ensemble mean approaches}

When analyzing the numerical experiments using multimodel ensembles such as the CMIP and AMIP simulations, there are some commonly used statistical approaches such as MEM, variance analysis, regression analysis, etc. When the MEM approach is used together with the latter two approaches, one may choose to calculate MEM before or after regression and variance analyses. In this study two different MEM approaches were used, and they have different implications as shown below. One approach is to calculate the variance or correlation for each model individually and then average the all models' variances or correlations together afterward, referred to as AMEM. AMEM is determined by the formula

$$
\overline{\sum_{i=1}^{n} f\left(X_{i}\right)},
$$

where $X_{i}$ represents the variables for the $i$ th model, $f\left(X_{i}\right)$ is a function representing a specific statistical method (e.g., standard deviation and variances in Figs. 1 and 2 and lead-lag correlation in Figs. 4 and 6), where $n$ is the 

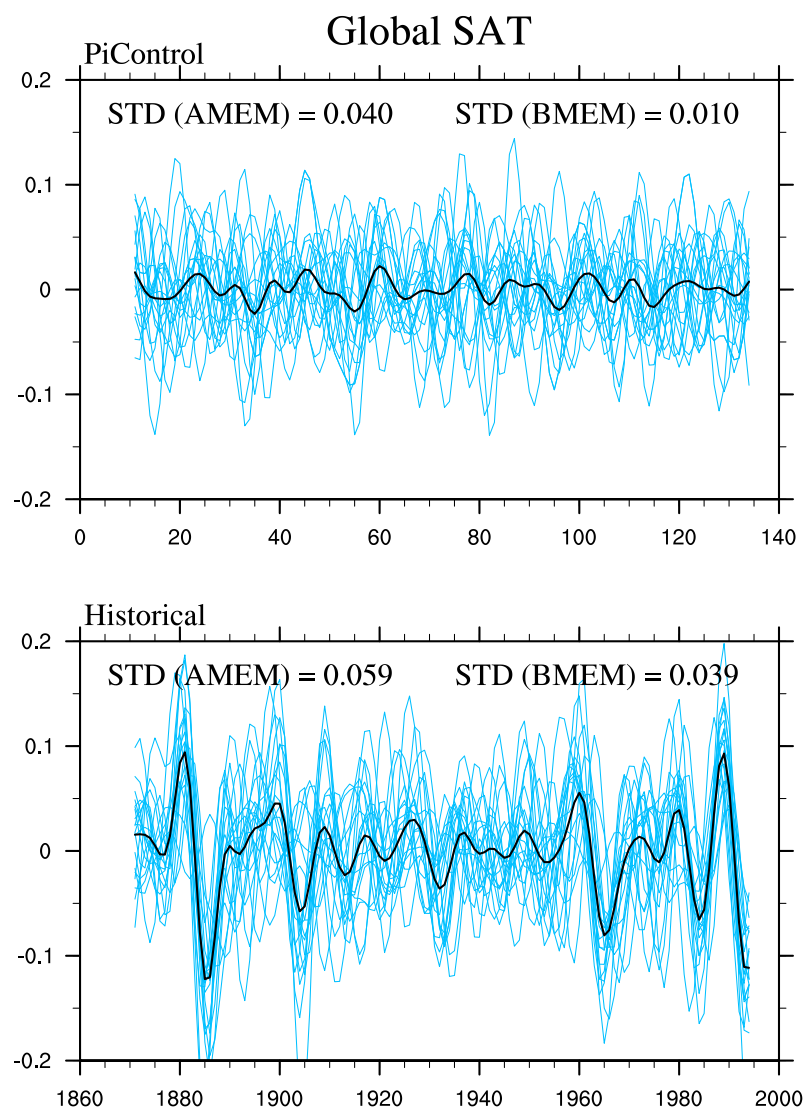

FIG. 1. The graphic explanation for the two MEM approaches (AMEM and BMEM). The time series of the global mean SAT in CTL and all-forcing runs in 21 CMIP5 models (blue line). The black lines show MEM results. The AMEM and BMEM standard deviation (STDs; ${ }^{\circ} \mathrm{C}$ ) are labeled.

number of models, and the overbar indicates the mean of multiple models. The AMEM contains some variability due to external forcing agents and internally generated processes in the climate system. Another approach is to calculate the MEM of a variable beforehand and then calculate the variances or correlations of the MEM; this approach is BMEM. BMEM is formulated as

$$
f\left(\overline{\sum_{i=1}^{n} X_{i}}\right) .
$$

For BMEM, by averaging over many members of CMIP models, where each is started from different initial conditions, forced climate change can be separated from the model's internal variability, which theoretically separates only the effect of external forcing.

To better understand what the BMEM and AMEM approaches represent, the time series of global mean SAT in both CTL and all-forcing runs are displayed in Fig. 1. In the CTL run, the time evolutions of the global mean SAT are stochastic in all models. After the MEM, the time series of the global mean SAT has a very weak oscillation and the BMEM standard deviation (STD) is $0.01^{\circ} \mathrm{C}$. However, because of the internal climate variability, the AMEM STD is relatively large $\left(0.04^{\circ} \mathrm{C}\right)$. In the all-forcing run, the time evolution of the global mean SAT in all models shows certain consistencies, indicating that the global mean SAT from multiple members varies in phase. The BMEM time series has an obvious decadal change; the BMEM STD is about $0.039^{\circ} \mathrm{C}$. These results indicate significant modulation of decadal variability is imposed by external forcing. The AMEM STD in the allforcing run is about $0.059^{\circ} \mathrm{C}$, demonstrating the combined influences of external forcing and internal variability.

\section{c. Cases selected for composite analysis}

We calculated 10-yr moving linear trends of the original global mean with no bandpass filter for SAT from 1850 to 2005 for each model in the all-forcing runs and then assigned the decades with top three strongest (weakest) linear trends as the accelerated warming (hiatus) decades, which were all greater (less) than $0.3^{\circ} \mathrm{Cdecade}^{-1}$ $\left(-0.15^{\circ} \mathrm{C}\right.$ decade $\left.^{-1}\right)($ Meehl et al. 2011, 2013; Song et al. 2014). Note that there was no overlap among any decade for each model. Based on the cases in each model, we first calculated the multicase mean of each model, and then took the composite mean of each model to obtain the MEM. This ensured a uniform weighting of each model's contribution to the MEM. To construct the geographical distribution of the MEM, the models' results were regridded to a $1^{\circ} \times 1^{\circ}$ grid (bilinear interpolation).

\section{Results}

\section{a. Enhanced decadal variability}

The AMEM STDs of global mean SAT for unforced and forced simulations are shown in Fig. 2a. For allforcing runs, the STDs show a significant increase relative to those in CTL runs, at the $95 \%$ confidence level. The STDs increase from $0.036^{\circ} \pm 0.013^{\circ} \mathrm{C}$ in CTL runs to $0.057^{\circ} \pm 0.012^{\circ} \mathrm{C}$ in all-forcing runs. Furthermore, natural forcing contributes most to the enhanced amplitude among all forcing agents, while the STDs in the GHG forcing runs do not exhibit any significant difference to those in the CTL runs. Figure $2 b$ shows the ratio of the variance of global mean SAT using the BMEM approach to that using the AMEM approach for the four groups of simulations with different external forcings. As explained in section 2, the AMEM approach presents the combined variations resulting from external climate forcing agents and internally generated processes, while the BMEM approach mainly highlights the externally forced signals. 
(a) St Dev.

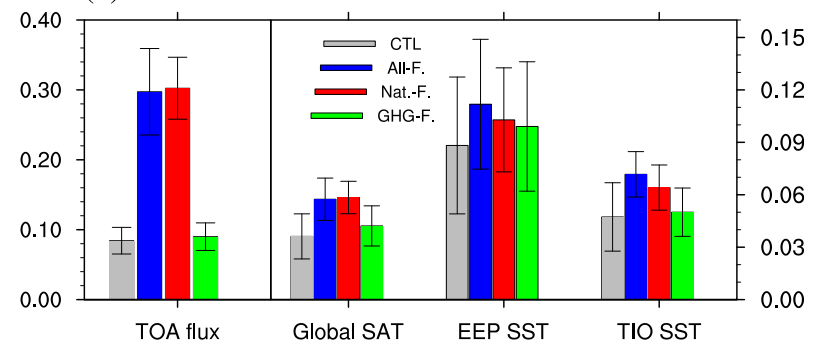

(b) Ratio of Var.

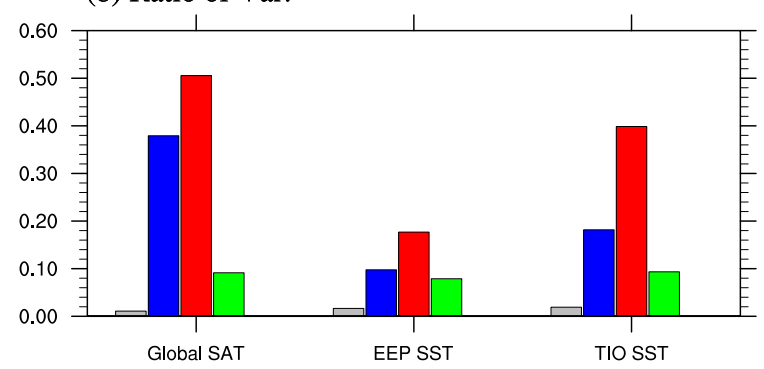

FIG. 2. (a) The AMEM STD of the net radiative fluxes at the top of the atmosphere $\left(\mathrm{W} \mathrm{m}^{-2}\right)$, the global mean SAT $\left({ }^{\circ} \mathrm{C}\right)$, and the eastern equatorial Pacific (EEP) SST $\left({ }^{\circ} \mathrm{C}\right)$ and tropical Indian Ocean (TIO) SST $\left({ }^{\circ} \mathrm{C}\right)$ for the CTL (gray; 39 models), all-forcing (blue; 21 models), GHG-forcing (red; 16 models), and naturalforcing (green; 16 models) runs, respectively. Error bars represent the intermodel standard deviation. (b) As in (a), but for the ratio of variances between BMEM and AMEM in the four simulations.

Hence, the ratios in the four groups of simulations are all less than 1 . In the CTL run, the BMEM variance can only explain $1 \%$ of the AMEM variance, indicating strong cancellation of temperature anomalies (i.e., different decadal phases) from the different coupled models. Under the almost consistently observed external forcing in the twentieth century, however, the decadal temperature anomalies only partially cancel each other out in these simulations. In all-forcing runs the ratio of variances from BMEM to AMEM is about 0.38, much larger than that in CTL runs. Furthermore, in natural-forcing runs the ratio is about 0.51 , indicating that the natural forcing contributes approximately $50 \%$ of total variance in this simulation. In other words, the decadal changes in SAT are independent of each other in the CTL runs without external forcing, but they exhibit considerable consistency among other simulations with external forcing, especially the natural forcing. This implies that the SAT decadal variability to some extent follows the decadal changes of external forcing. These results suggest that the external forcing, especially natural forcing, can induce the enhanced decadal variability of global mean SAT through enhancing amplitude (Fig. 2a) and modulating phase (Fig. 2b). These results are supported by many previous studies of strong tropical volcanic eruptions; such events lead to changes in atmospheric and oceanic circulations and modulate climate variations on scales ranging from interannual to decadal (Otterå et al. 2010; Wang et al. 2012; Zanchettin et al. 2012; Ohba et al. 2013; Cui et al. 2014), which then influence SAT. Further analysis confirms that this enhanced variability does not depend on the different sample sizes in the four simulations. Data from 16 CMIP5 models that contain four simulations together (see Table 1) also exhibit the significantly enhanced decadal variability of SAT (Fig. S1 in the supplemental material), similar to the above results. Furthermore, each model of the 16 CMIP5 models also shows the consistently enhanced amplitude induced by all external forcings, especially by natural forcing (Fig. 3a).

Figure 4 further reveals the geographic distribution of the ratios of the AMEM variances from all-forcing runs to those from CTL runs. Increased decadal variances exist mainly in the tropics. In particular, the tropical Indian Ocean (TIO; $20^{\circ} \mathrm{S}-20^{\circ} \mathrm{N}, 40^{\circ}-110^{\circ} \mathrm{E}$ ) stands out as the region with the more significant variations than the eastern equatorial Pacific (EEP; $20^{\circ} \mathrm{S}-20^{\circ} \mathrm{N}, 170^{\circ} \mathrm{E}-80^{\circ} \mathrm{W}$ ) (Figs. 2 and 4; see also Fig. S1). As shown in Fig. 2a, the increased SST STD for the regional mean TIO is more significant than that for the EEP in all-forcing runs. Similar characteristics also appear in the natural-forcing runs. The ratio of TIO SST variances between BMEM and AMEM in the natural-forcing runs is also very high, at around 0.4, but the ratio for EEP SST is relatively weak (Fig. 2b). The time series of regionally averaged TIO SST and EEP SST in both the CTL and all-forcing runs clearly exhibit modulations caused by external forcing, with enhanced amplitudes and a relatively consistent decadal phase for TIO SST, albeit less so for EEP SST (Fig. S2 in the supplemental material). The amplitudes changes for TIO SST and EEP SST are also verified by the 16 CMIP5 models that conduct all four groups of simulations (Figs. 3b and 3c; see also Fig. S1).

\section{b. The relationship between $S A T$ and radiative flux at the top of the atmosphere}

To detect the influence of external radiative forcing on the global mean SAT, we examine the decadal variations of global radiative forcing in four groups of simulations. Because of a lack of direct radiative forcing information for each model, we use the net radiation at the top of the atmosphere (TOA) (Fig. 2a) as the radiative forcing affecting the climate system. As shown in Fig. 2a, the decadal variations of radiative forcing in the four groups of simulations show changes consistent with those of the global mean SAT; this indicates that these forcings may directly drive the global mean SAT. In particular, compared with the variations in the CTL run, the radiative forcings from both the all- and naturalforcing runs have significantly increased variances, but 
(a) Global SAT St Dev.

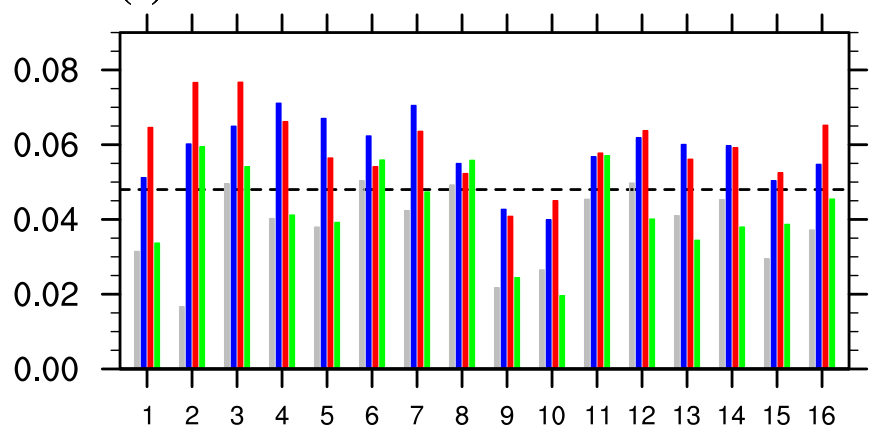

(b) TIO SST St Dev.

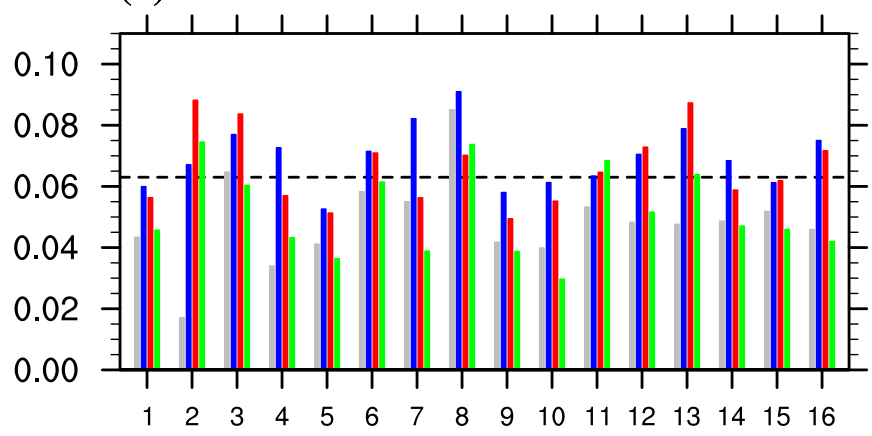

CSIRO-Mk3-6-0

GFDL-CM3

GFDL-ESM2M

9 GISS-E2-H

10 GISS-E2-R

11 HadGEM2-ES

12 IPSL-CM5A-LR

13 MIROC-ESM

14MIROC-ESM-CHEM

(c) EEP SST St Dev.

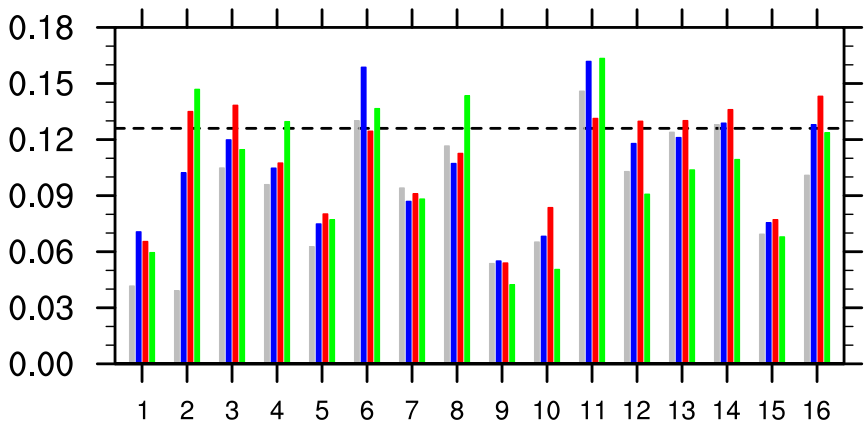

15 MRI-CGCM3

16 NorESM1-M

FIG. 3. (a) The STD $\left({ }^{\circ} \mathrm{C}\right.$ ) of global mean SAT in CTL (gray), all-forcing (blue), natural-forcing (red), and GHG-forcing (green) run for each model in 16 CMIP5 models that contain four simulations together (see Table 1), respectively. (b) As in (a), but for TIO SST. (c) As in (a), but for EEP SST. The maximum magnitudes (AMEM STD + one intermodel STD) for 16 models from the CTL run are indicated by the horizontal dashed lines. Detailed values (error bars) for four simulations in 16 models can be found in Fig. S1 of the supplementary information.

the variance of radiative forcing in the GHG-forcing run hardly increases. It is noteworthy that although the STD of the CTL and GHG-forcing runs are similar, the decadal variations of radiative forcing have different causes. In the CTL runs, there is no external radiative forcing but the net shortwave (SW) and longwave (LW) radiative fluxes at the TOA still exhibit considerable decadal variability resulting from internal climate feedbacks, such as cloud-radiation feedback. However, variations in the GHG-forcing runs combine the effects of external GHG forcing and internal climate feedbacks.
To further understand the relationship between external radiative forcing and the global mean SAT on a decadal time scale, the lead-lag correlations between global mean TOA net SW radiative flux and SAT are shown in Fig. 5. In the CTL runs, the AMEM correlations between TOA net SW radiative flux and global mean SAT have maximum correlation coefficients at about $0.5 \pm 0.2$ with a lag of approximately 13 months (TOA net SW radiative flux leading SAT). This significantly positive lag correlation should be related to the cloud-radiation feedbacks in the climate system. An 


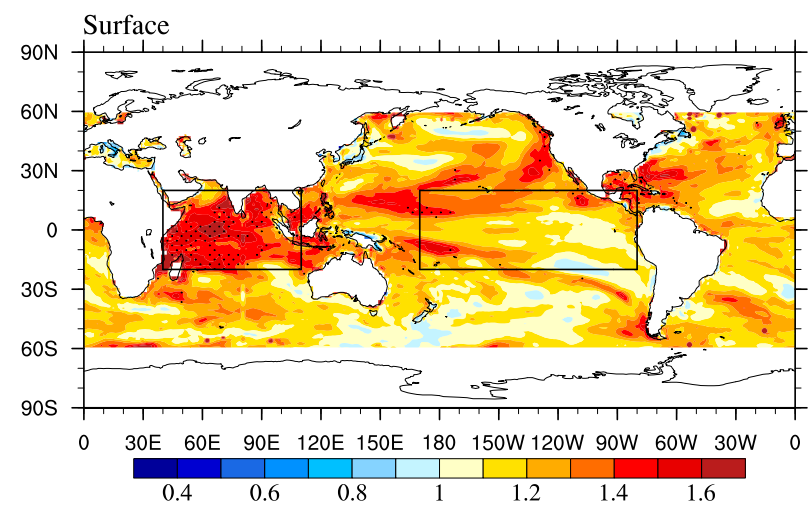

FIG. 4. The AMEM ratios of the SST variance in all-forcing run to those in CTL run. The stippling indicates 17 or more models that agree on increased amplitude. Black boxes present the regions of the EEP and TIO. Because of the large differences and disagreements among CMIP5 models in simulating high-latitude variability, in this figure only the ratios between $60^{\circ} \mathrm{S}$ and $60^{\circ} \mathrm{N}$ are displayed.

anomalous SST cooling leads to a decrease in cloud fraction and thus an increase in net SW radiation at TOA, which in turn warms the surface and subsurface temperatures with a lag of about several months. Under the external forcing, the lag correlations for the AMEM approach became stronger $(0.74 \pm 0.13$ in all-forcing runs, $0.81 \pm 0.09$ in natural-forcing runs, and $0.61 \pm 0.22$ in GHG-forcing runs), indicating the stronger response of
SAT to the radiative flux at the TOA. The BMEM correlations that mainly highlight the forced climate changes are extremely weak in the CTL runs because of the offsets among random internal climate anomalies. Consequently, the lag correlation shows a significant reduction relative to AMEM in CTL runs. On the other hand, in all-forcing runs, the forced climate change has a significantly increased lag correlation ( 0.96 for a 13-month lag) in contrast to that in AMEM. A high correlation is maintained in natural-forcing runs ( 0.97 for a 13-month lag), and correlation weakens slightly but remains significant in GHGforcing runs ( 0.74 for a 17 -month lag). All these results indicate that under the modulation of external forcing, the interactions between global mean SAT and TOA net SW flux become stronger. The comparisons for the two MEM correlations in the unforced and forced simulations mentioned above once again confirm the significant impact on decadal variability of SAT by external forcing. Comparing the lag correlation coefficients for different external forcing agents, the natural-forcing agent has the largest impact on the decadal time scale.

The warming hiatus, ongoing since 1998 (Easterling and Wehner 2009), has been extensively investigated and there is significant debate about its possible causes (Solomon et al. 2010; Kaufmann et al. 2011; Meehl et al. 2011, 2013; Kosaka and Xie 2013; Tung and Zhou 2013; England et al. 2014; McGregor et al. 2014; Song et al. 2014). Using CCSM4 in a representative concentration (a) PiControl

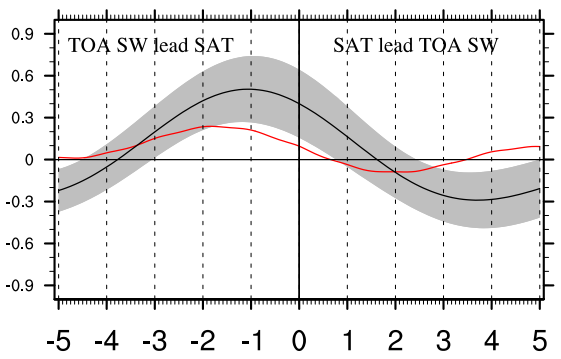

(c) HisNat

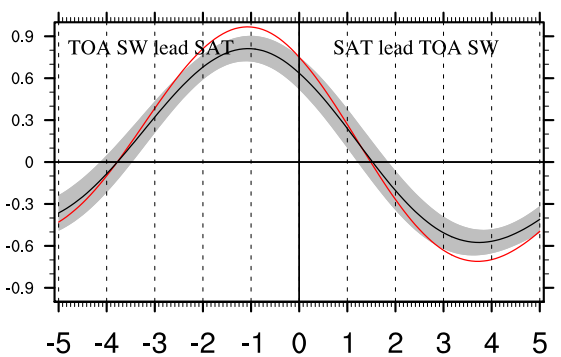

(b) Historical

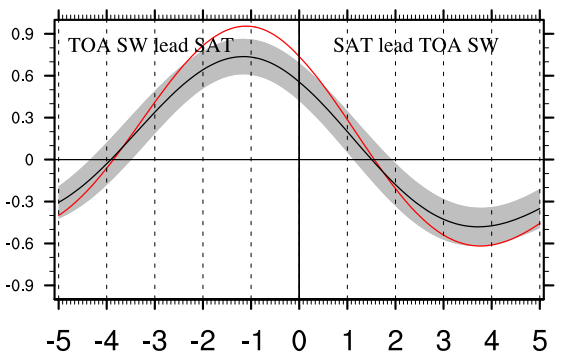

(d) HisGHG

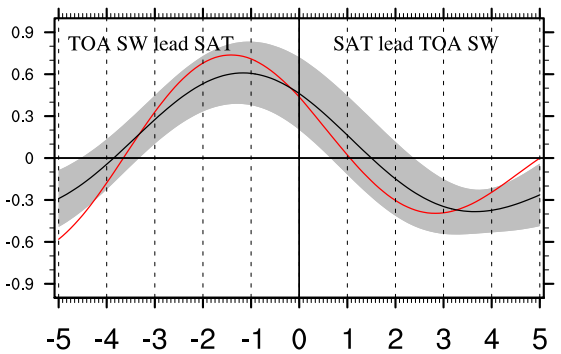

FIG. 5. The lead-lag correlations between the TOA net SW radiative fluxes and global mean SAT in the (a) CTL, (b) all-forcing, (c) natural-forcing, and (d) GHG-forcing runs. The black (red) lines are for AMEM (BMEM) correlations. The shading represents one standard deviation of the intermodel correlations. Negative (positive) values on the $x$ axis indicate the years that TOA net SW fluxes lead (lag) SAT. 

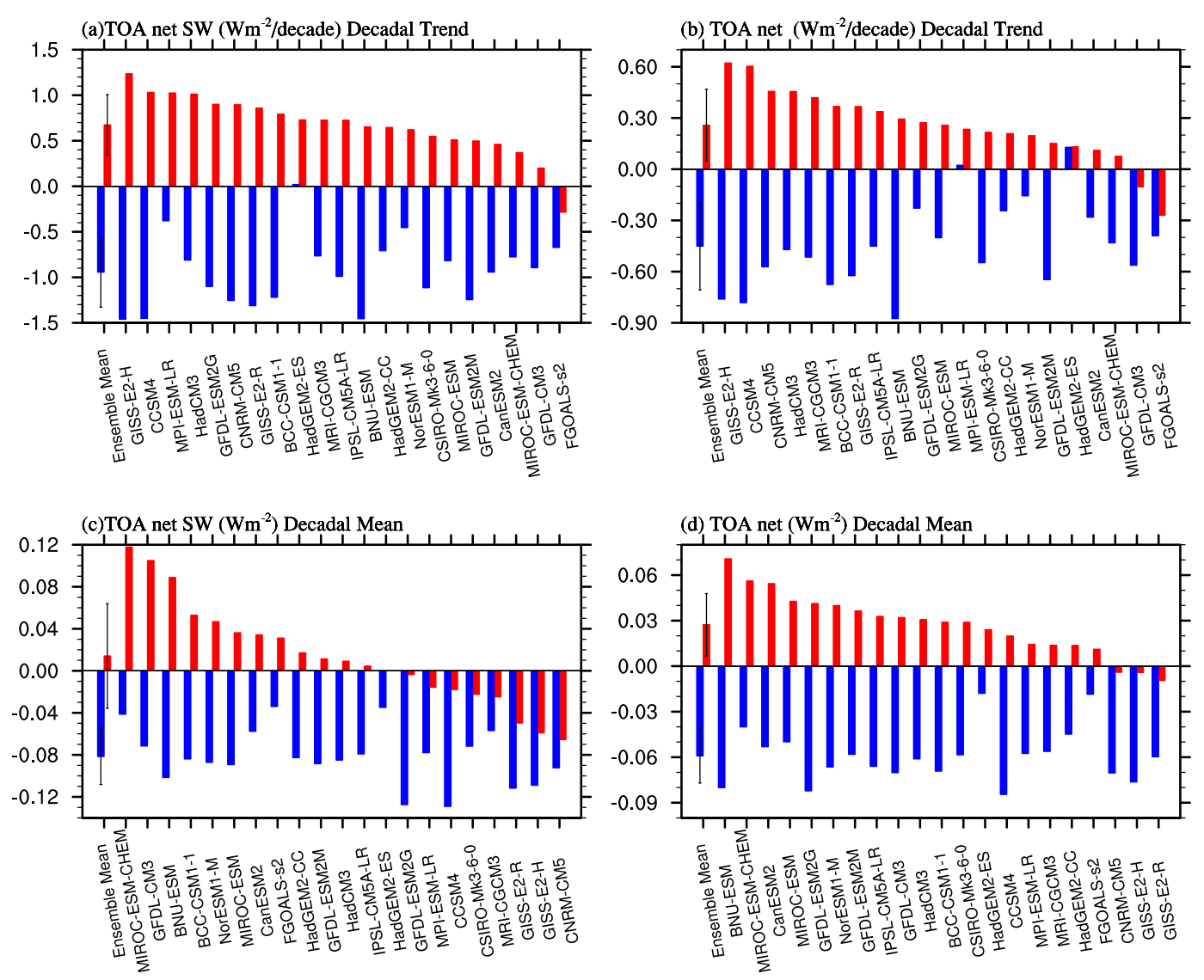

FIG. 6. (a) Composite TOA net SW radiative flux linear trends in all-forcing runs during hiatus (blue bars) and accelerated (red bars) warming decades with a lag of 13 months (TOA net SW flux leading SAT). (b) As in (a), but for TOA net flux. (c),(d) As in (a),(b), but for the simultaneous decadal means. The first bars are for AMEM result in each panel. Error bars represent one STD of the intermodel results.

pathway 4.5 (RCP4.5) simulation, Meehl et al. (2013, hereafter MH13) showed that there was no significant difference in the energy imbalance at the TOA during the hiatus and accelerated warming decades. These results are somewhat different from our findings (Fig. 5). Given the close correlation between TOA net radiative fluxes and the full-depth ocean heat content (OHC) trend on the decadal time scale, but the weak relationship with SAT/SST trend (Palmer et al. 2011; Song et al. 2014), oceanic dynamic processes may play important roles in modulating the SST changes. To demonstrate these dynamic modulation processes, based on the significant lag correlations described above, we composited TOA net SW radiative flux linear trends for all-forcing runs during the hiatus and accelerated warming decades (see section 2 for the detailed case selections). When net SW radiative flux leads by 13 months, the linear trend for net SW radiative flux at the TOA shows the consistent change with the global mean SAT trend for every model (Fig. 6a). During hiatus decades, there are significant negative linear trends in TOA net SW flux in all models except HadGEM2-ES. The TOA net SW trend for AMEM is $-0.94 \pm 0.38 \mathrm{~W} \mathrm{~m}^{-2}$ decade $^{-1}$. However, during the accelerated warming decades, significant and positive linear trends for TOA net SW radiative flux occur in all models except for FGOALS-s2. The AMEM trend is $0.67 \pm 0.34 \mathrm{~W} \mathrm{~m}^{-2} \mathrm{decade}^{-1}$. There are significant differences between the hiatus and accelerated warming decades at the $99 \%$ confidence level. The TOA net fluxes have similar features to the TOA net SW flux, with a relatively weaker trend (Fig. 6b). This once again indicates the significant lead-lag correlation between TOA flux and SAT.

To further compare against MH13's results, the same composites were calculated using simultaneous decadal means of the TOA flux during the hiatus and accelerated warming decades (Figs. 6c,d). During hiatus decades, an almost consistently negative decadal mean for TOA net SW flux is found for each model. Not only that, but the decadal means for TOA net flux also show consistent changes with the global mean SAT in each model, indicating simultaneous correlation between TOA flux and SAT. In the present study, both for the decadal linear 
trend and decadal mean, the CCSM4 model has significant differences in the energy imbalance at the TOA during the hiatus and accelerated warming decades as for the AMEM results, different from the results of MH13. One possible explanation for this is that MH13 examine the RCP4.5 simulations with continually increased GHGs; these produce more significant radiative forcings than those in the historical simulations. Another reason is could be our use of multimodel results, allowing for a more thorough comparison. However, in contrast to this simultaneous correlation, there is a closer relationship when TOA net SW flux leads SAT by about 13 months. An alternative explanation is that incoming TOA SW radiation heats the sea surface first, thereby changing the surface wind and inducing anomalous air-sea interactions and oceanic circulations. These dynamical processes modulate the SST and attain the new equilibrium state at a lag of approximately 13 months. In contrast, MH13 only highlighted the SST transient responses to radiative forcings. To conclude, when considering dynamic adjustment processes, there is a significantly delayed response of the SST to radiative fluxes at the TOA.

Based on the significant lag correlations, the geographic distributions of the SST's delayed response to the global mean net $\mathrm{SW}$ radiative fluxes at the TOA are not uniform (Fig. 7). The AMEM correlations for both unforced and forced simulations have significantly positive correlations over the tropics. These positive correlations are weaker in CTL runs than in external forcing simulations. These also indicate that the external forcing has the potential to modulate the decadal variability of the surface temperature. Furthermore, different simulations have different geographic distributions of correlations. The correlation coefficients are much stronger in all-forcing runs and natural-forcing runs than that in CTL runs, with the most significant regions at the equatorial western Pacific and the Indian Ocean. But in CTL and GHG-forcing runs, the correlations are significantly positive with an IPO-like pattern in the Pacific. In contrast to the AMEM correlations, the BMEM, which only highlights the contributions of external forcings, shows more significantly positive correlations in the three external forcing simulations, and less significant correlations in the CTL run (Fig. 7). These results once again indicate a significant modulation in decadal variability induced by external forcing; thus, the response of the surface temperature to TOA net $\mathrm{SW}$ radiative flux is more consistent.

Both AMEM and BMEM patterns in all-forcing runs, especially in natural-forcing runs, indicate that the TIO SST has a stronger response to TOA net SW radiative forcing than EEP SST. For this reason, Figs. 2-4 show that forced decadal climate variability has a more robust enhancement in TIO SST than that in EEP SST, and this characteristic could extend to the upper $50 \mathrm{~m}$ of the ocean (Fig. 8a). However, from around 0 to $700 \mathrm{~m}$ below the ocean's surface, a robust increase in OHC decadal variances occurs in the midlatitude Pacific Ocean, and the variances in TIO are roughly equivalent to those in the EEP (Fig. 8b). These features may be associated with the Indian Ocean's shallower thermocline. A shallow thermocline and mixed layer are more sensitive to atmospheric changes induced by anomalous radiative fluxes and stronger coupling between the subsurface and SST: these lead to strong SST anomalies (Duvel et al. 2004; Vialard et al. 2009a,b). This explains why TIO SST is more sensitive to TOA net SW flux than EEP SST.

However, in GHG-forcing runs, both the AMEM and BMEM correlations have their most significant correlations in the Pacific, with a positive IPO-like pattern. This IPO-like response to global warming in the tropical $\mathrm{Pa}-$ cific has already been confirmed by many previous studies (Knutson and Manabe 1995; Meehl and Washington 1996; Yu and Boer 2002; Meehl et al. 2009; Xie et al. 2010; Luo et al. 2015). Progress in determining the physical mechanism has been made, though it is not yet certain. Suggested causes include greater evaporative cooling over the warm pool than the cold tongue (Knutson and Manabe 1995), strong surface latent heat flux exchange in the tropics (Liu et al. 2005), and a wind-evaporation-SST feedback mechanism (Xie et al. 2010).

Comparing the global SAT BMEM responses to the natural-forcing runs with those of the GHG-forcing runs (Fig. 7), the tropical responses are significant relative to those of the middle-to-high latitudes, mainly characterized in GHG-forcing run. However, there are global nearuniform responses in the natural-forcing runs: we suggest that two processes may combine to cause this effect. One is the direct heating from radiative forcing, such as solar radiative changes and decreased incoming radiative fluxes due to volcanic eruptions, which affect the SST changes in tropics. Second, volcanic aerosols can also heat the tropical stratosphere, thus impacting stratospheric dynamical processes and inducing changes in the polar vortex: these contribute to the SAT changes in high latitudes (Stenchikov et al. 2006; Driscoll et al. 2012; Wang et al. 2012). Both processes contribute the global-basin responses of SAT to natural forcings.

However, although both natural forcing and GHG forcings affect the tropics, the spatial responses in the tropical Pacific have different features (Fig. 7). In the natural-forcing run, the tropical Pacific zonal SST gradient increases with a La Niña-like pattern and anomalous east wind stress when the warming is due to increased natural radiation. But as a result of increased greenhouse gas in GHG-forcing run, the tropical Pacific 


\section{AMEM Cor.}

PiControl TOA net SW (lead 13 months) vs SAT

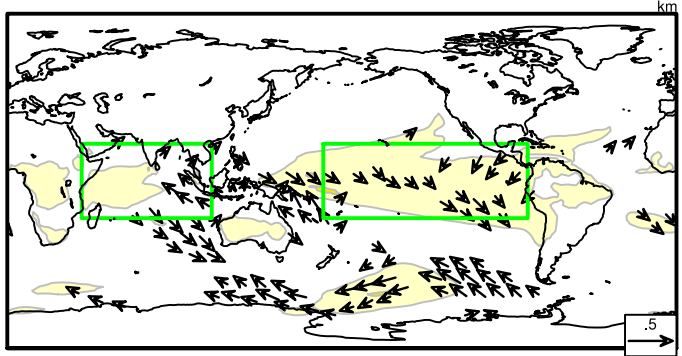

HisNat TOA net SW (lead 13 months) vs SAT

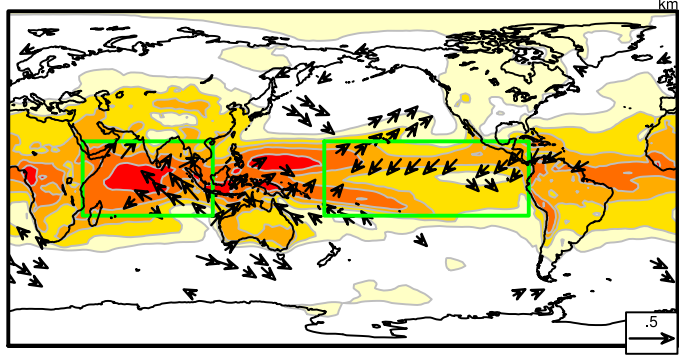

Historical TOA net SW (lead 13 months) vs SAT

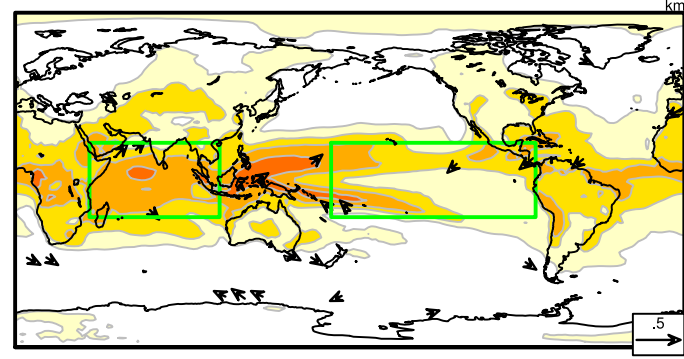

HisGHG TOA net SW (lead 13 months) vs SAT

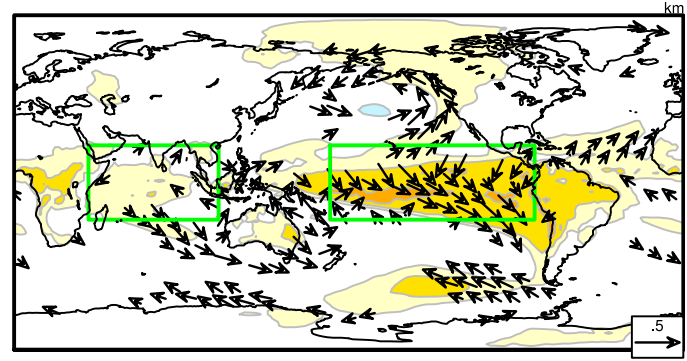

$\begin{array}{llllllllllllllll}-0.9 & -0.8 & -0.7 & -0.6 & -0.5 & -0.4 & -0.3 & -0.2 & 0.2 & 0.3 & 0.4 & 0.5 & 0.6 & 0.7 & 0.8 & 0.9\end{array}$

BMEM Cor.

PiControl TOA net SW (lead 19 months) vs SAT

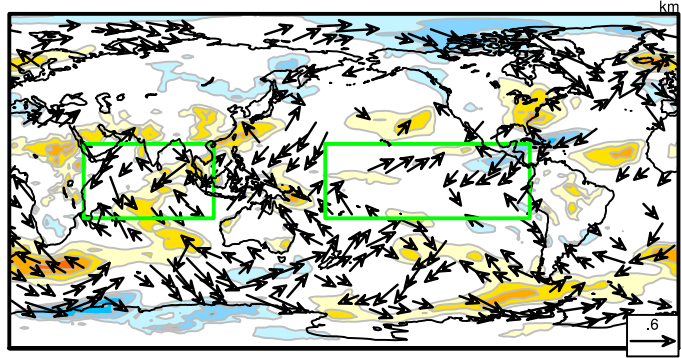

HisNat TOA net SW (lead 13 months) vs SAT

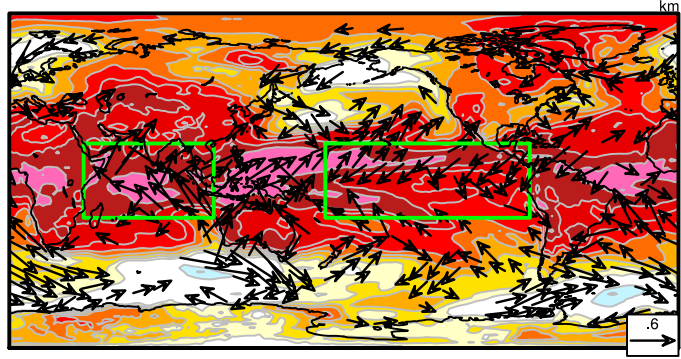

Historical TOA net SW (lead 13 months) vs SAT

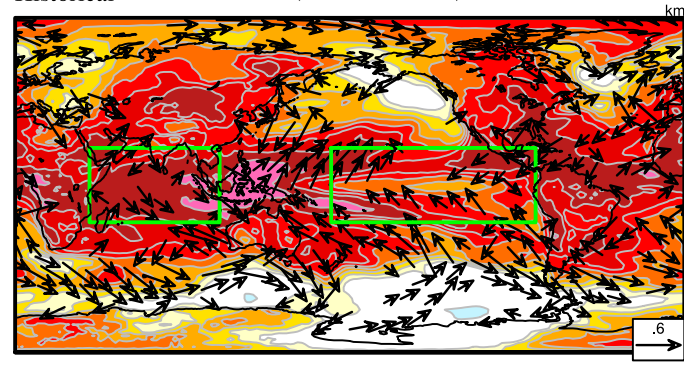

HisGHG TOA net SW (lead 17 months) vs SAT

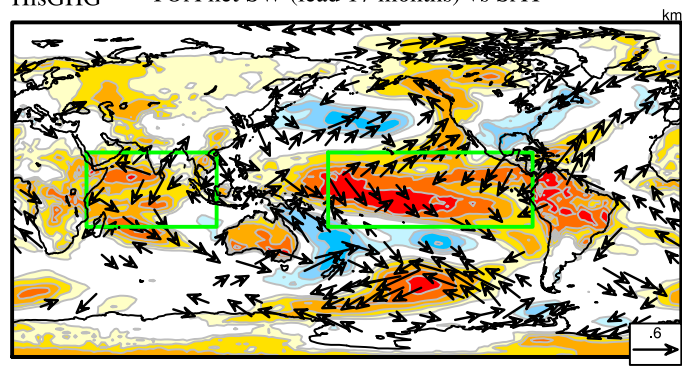

\begin{tabular}{lllll|lll|l|l|l|l|l|l|ll|ll|l} 
& & & & & & & & & & & & & & & & & \\
-0.9 & -0.8 & -0.7 & -0.6 & -0.5 & -0.4 & -0.3 & -0.2 & 0.2 & 0.3 & 0.4 & 0.5 & 0.6 & 0.7 & 0.8 & 0.9
\end{tabular}

FIG. 7. (top) The geographic distributions for the AMEM correlation coefficients between global mean TOA net SW radiative flux and SAT (shading) and wind stress (vector), with a lag of 13 months (TOA net SW flux leading SAT) in the CTL, all-forcing, natural-forcing, and GHG-forcing runs, respectively. (bottom) As at (top), but for the BMEM correlation coefficients with a lag of 19 months in CTL, a lag of 13 months in all-forcing run and naturalforcing run, and a lag of 17 months in GHG-forcing run. Green boxes indicate the EEP and TIO regions. 
(a) Upper 50m

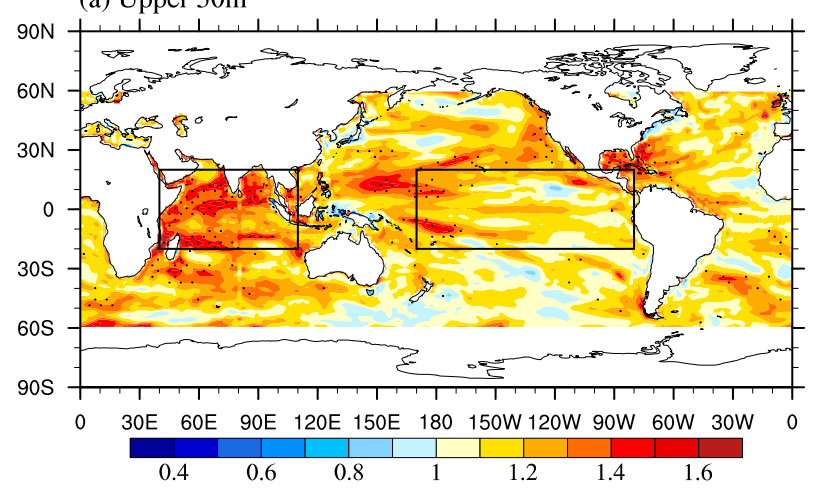

(b) Upper $700 \mathrm{~m}$

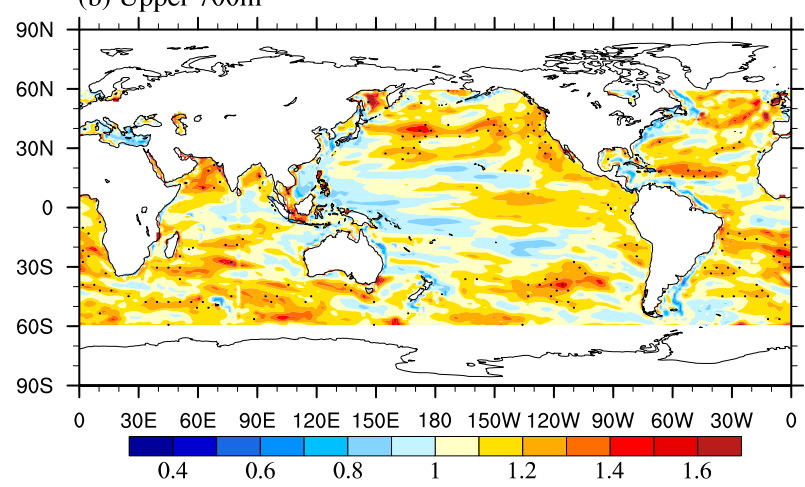

FIG. 8. (a) As in Fig. 4, but for OHC in the upper $50 \mathrm{~m}$ of the ocean. The stippling indicates 15 or more models that agree on increased amplitude. (b) As in Fig. 4, but for OHC in the upper $700 \mathrm{~m}$ of the ocean. The stippling indicates 14 or more models that agree on increased amplitude. Black boxes in (a) indicate the EEP and TIO regions.

SST gradient decreases with an El Niño-like pattern and west wind anomalies. These different SST gradients produce different climate responses such as global precipitation (Liu et al. 2013). Using paleo-proxy evidence and model simulations, Liu et al. (2013) showed that, for the same global SAT increase, the global precipitation change due to natural forcing is more than that resulting from GHG forcing. These differences are consistent with the atmospheric static stability, which depends on the type of heating. Tropospheric cooling is less with increased GHG concentrations, because of the additional radiation-absorbing species in the troposphere, than that with increased solar heating, which is concentrated at Earth's surface.

\section{c. Contributions from EEP and TIO SST to global mean $S A T$}

The warming SST in the tropics can contribute to the global SAT through air-sea interaction and ocean dynamics (Alexander et al. 2002; Luo et al. 2012). The scatter diagram in Fig. 9 shows that during the hiatus decades in all-forcing runs, both TIO SST and EEP SST trends show significantly linear correlations with global mean SAT trends, with correlation coefficients of 0.68 and 0.59 , respectively. Kosaka and Xie (2013) had to prescribe the observed SST in the EEP in order to get the hiatus and deduce the prominent role for EEP. But our study shows that TIO SST also has a significant correlation with global mean SAT. This suggests that not only the EEP SST but also the TIO SST plays an important role in impacting the global mean SAT during hiatus decades. Given the close relationship between the Indian and Pacific Oceans, when considering the recent cooling of the EEP SST described by Kosaka and Xie (2013), it remains possible that through the teleconnection (Latif and Barnett 1995; Lau 1997; Alexander et al. 2002) in coupled models the EEP SST can also induce the changes in TIO SST, and thus the important contributions from TIO SST to global SAT may have been implicit in their results. Therefore, distinguishing the relative roles of EEP SST and TIO SST in influencing global SAT requires further study. In addition, given the different spatial responses to the external radiative changes (GHG forcing and natural forcing; Fig. 7), their roles under different forcing agents also need further investigation.

In the Pacific, the IPO for the basinwide pattern is the most important decadal variation and is a key component for the prediction of future climate change. The IPO is typically defined as the second empirical orthogonal function (EOF) of low-pass filtered SST in the Pacific (e.g., Parker et al. 2007). In the present study, after the bandpass filter, the first EOF of the Pacific SST is for the IPO (e.g., Meehl et al. 2009). Using this method, an almost consistent IPO pattern appears in all four types of simulation, with a broad area of positive values in the tropical Pacific and along the west coasts of North and South America, and negative values in the northwest and southwest Pacific (Fig. S3 in the supplemental material). We define the IPO index as the SST anomaly difference between the eastern tropical Pacific $\left(10^{\circ} \mathrm{S}-6^{\circ} \mathrm{N}\right.$, $\left.110^{\circ}-160^{\circ} \mathrm{W}\right)$ and the North Pacific $\left(30^{\circ}-45^{\circ} \mathrm{N}, 145^{\circ} \mathrm{W}-180^{\circ}\right)$. The IPO index is well correlated with the IPO defined by the EOF method (Dong et al. 2014). Using the IPO index, rather than regionally averaged EEP SST, we identify the contribution of the Pacific SST to global SAT in different external radiative forcing agents. The lead-lag correlations between the IPO index and global mean SAT are shown in Fig. 10. For the AMEM, both unforced and forced simulations show significant positive correlation between the IPO index and the global mean SAT. This relationship depends on the internal variability (Fig. 10a). However, for the BMEM, this only represents the external forcing results: the correlations show different features in natural-forcing and GHG-forcing 


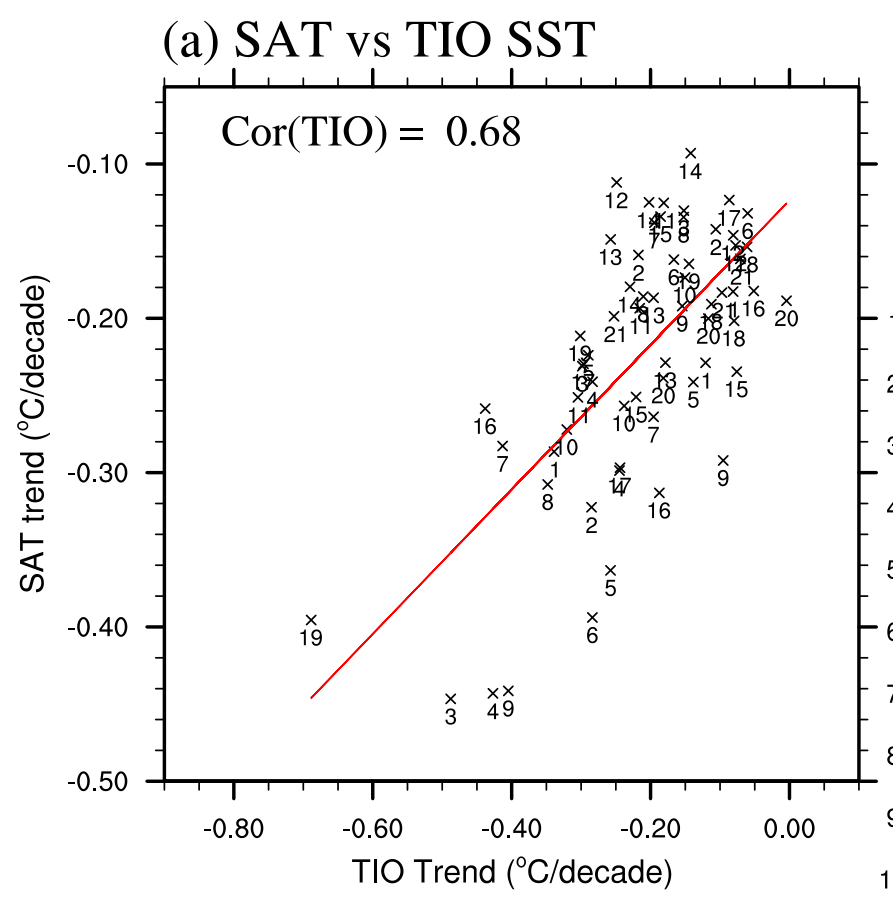

BCC-CSM1-1

BNU-ESM

3 CanESM2

$4 \quad$ CCSM 4

5 CNRM-CM5

6 CSIRO-Mk3-6-0

7 FGOALS-s2

8 GFDL-CM3

GFDL-ESM2G

0 GFDL-ESM2M

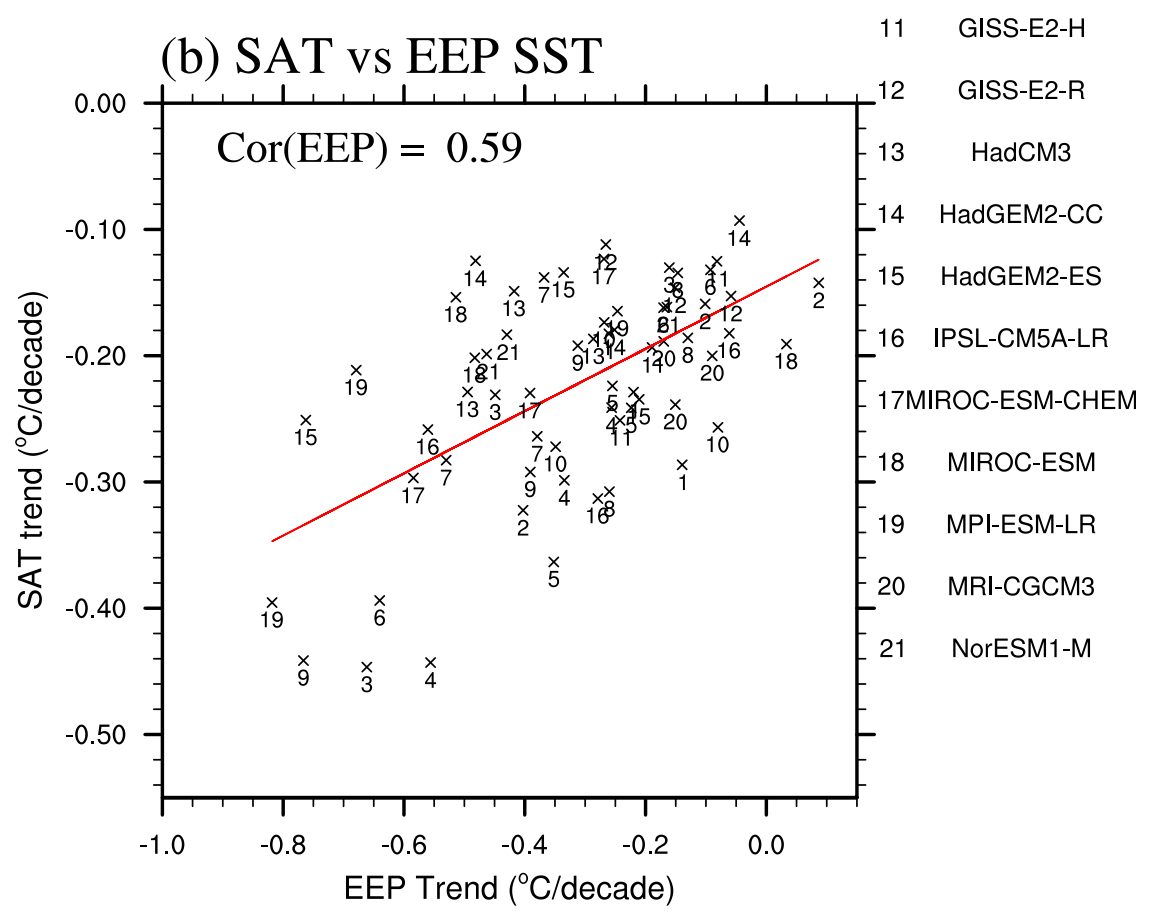

FIG. 9. Scatter diagram of the decadal linear trends of the global mean SAT vs the decadal linear trends of the regional mean SST in the (a) TIO and (b) EEP in hiatus decades for allforcing runs. The straight line is the best fit to the global mean SAT trends and TIO (EEP) SST trends, and has a correlation coefficient of $0.68(0.59)$.

simulations. In GHG-forcing runs, consistent with the inherent modulations, the IPO index shows the most significant correlation with global mean SAT (Fig. 10d). But in the natural-forcing run, a weak correlation appears with a lag of about $2.6 \mathrm{yr}$, when the global mean SAT leads IPO index (Fig. 10c). It is because the lag influences natural forcing that the AMEM correlation in natural-forcing runs is lower than that in GHG-forcing 
(a) PiControl

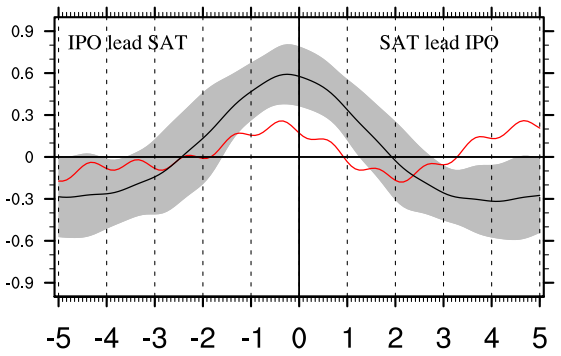

(c) HisNat

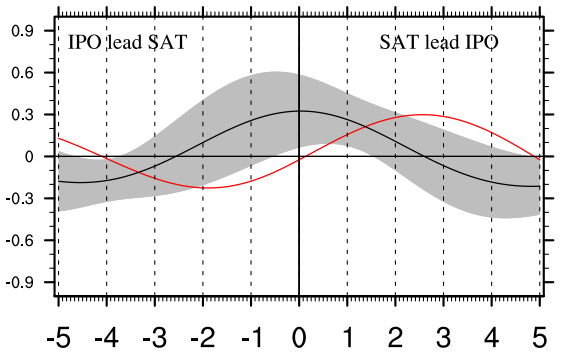

(b) Historical

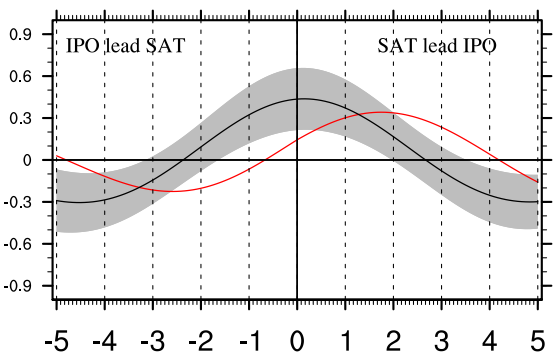

(d) HisGHG

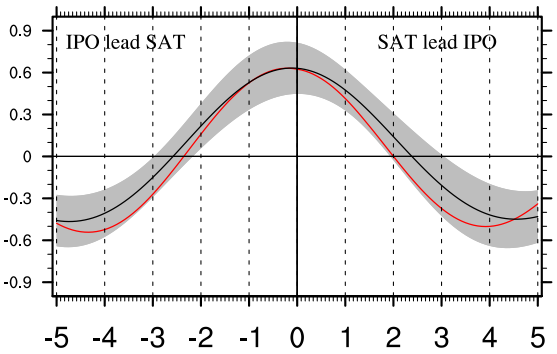

FIG. 10. As in Fig. 5, but for the correlations between the IPO index and global mean SAT.

runs. Therefore, under the GHG forcing, the correlation between IPO index and global mean SAT becomes closer. But it is less significant under the natural forcing.

The same approach is applied to discuss the contribution of TIO SST to global mean SAT. The lead-lag correlations between regionally averaged TIO SST and global mean SAT are shown in Fig. 11. Different from the Pacific, the TIO SST and global mean SAT in BMEM and AMEM show significant simultaneous positive correlations. These indicate that both the inherent climate variability (Fig. 11a) and the various external forcing agents (Figs. 11b-d) induce a close relationship between the TIO SST and SAT. Combing the results of Figs. 7 and 9-11, we conclude that the natural forcing (volcanic eruption and solar radiative forcings) leads to global SAT and TIO SST changes, which then result in IPO anomalies two years later. We further conclude that the GHG forcing first induces tropical SST anomalies (e.g., TIO SST and EEP SST), which forces the opposite SST signal appearing in the subtropical Pacific via teleconnection (Latif and Barnett 1995; Lau 1997; Alexander et al. 2002), thus generating an IPO pattern in the Pacific. These then contribute to the simultaneous changes of global SAT.

\section{Conclusions and discussion}

The present study of the latest CMIP5 simulations assesses the impacts of various external radiative forcing agents on the decadal variability of SAT. The MEM approach is applied before and after conducting variance and regression analysis, respectively termed BMEM and
AMEM. By comparing these two approaches, our study makes the possible quantitative comparisons of the SAT decadal changes in the CTL, all-forcing, natural-forcing, and GHG-forcing runs. We demonstrate that external forcing, especially natural forcing, can act on the decadal variability of the global mean SAT through enhancing its amplitude and modulating its phase. Furthermore, the enhanced variances are more significant in tropics because of the stronger air-sea interaction, which strengthens temperature anomalies induced by the external forcing. The relationship between external forcing and global SAT show that there is a significant 13-month-delayed response of the SAT to TOA net SW fluxes in all four groups of simulations, but with different spatial distributions of the global SAT responses to radiative forcing. In the GHG-forcing run, the most significant responses are concentrated in the tropics and generate an IPO-like pattern via teleconnection in the Pacific. In natural-forcing runs, there are global near-uniform responses, which may be the combined results of direct heating of the tropical SST by radiative forcing and changes in the stratospheric dynamical process induced by volcanic aerosols. In addition, comparing the SST responses in the tropics, more significant signals appear in the TIO SST than in the EEP. These features may be associated with the shallower ocean thermocline in the Indian Ocean than in the tropical Pacific.

Finally, we analyze the relative roles of EEP SST and TIO SST with regard to global SAT under different forcing agents. We find that not only the EEP SST (Kosaka and Xie 2013) but also the TIO SST impacts the 
(a) PiControl

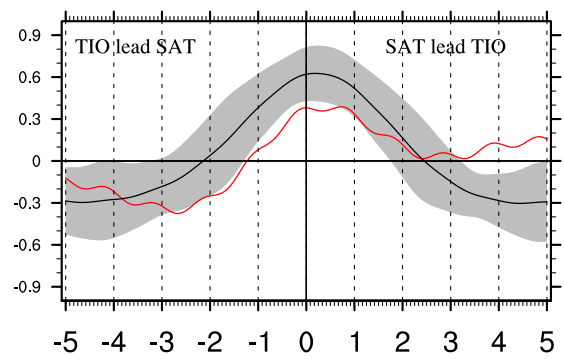

(c) HisNat

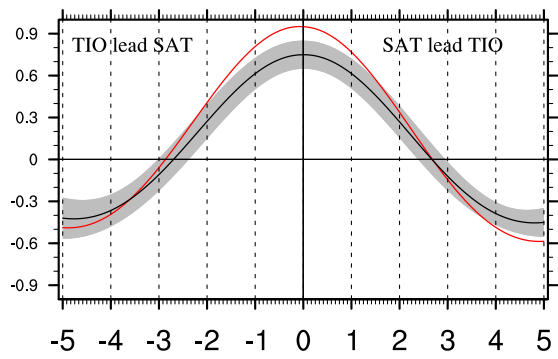

(b) Historical

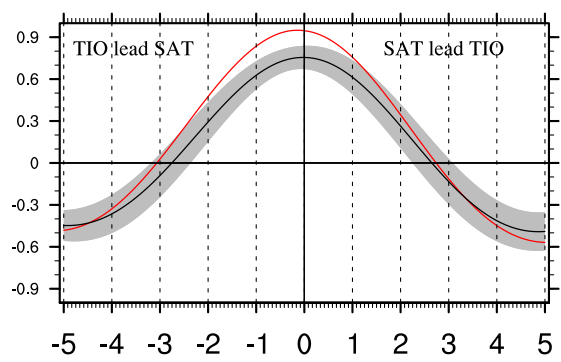

(d) HisGHG

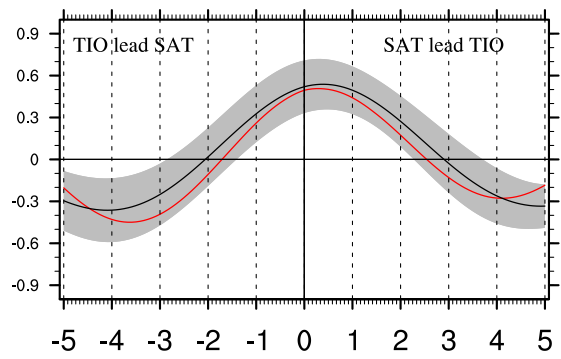

FIG. 11. As in Fig. 5, but for the correlations between the regionally averaged TIO SST and global mean SAT.

global mean SAT during hiatus decades. Furthermore, these have different physical mechanisms under the different external forcing agents. Natural forcing first leads to global SAT and TIO SST changes, which then result in the IPO anomalies two years later. GHG forcing instead first induces TIO SST and IPO anomalies, which then contribute to simultaneous changes of global SAT.

When considering oceanic dynamic adjustment processes, there is a significant 13-month-delayed response of the SST to TOA net SW fluxes. The 13-month lag approximately agrees with the study of White et al. (1997), where global mean SST had a maximum correlation with reconstructed solar irradiance for a lags of $1-2 \mathrm{yr}$ on the decadal time scale, and these signals were confined to the upper $100 \mathrm{~m}$ or so of the ocean. As suggested by White et al. (1997), these time lags can be explained by the radiative balance between changing solar irradiances and LW outgoing radiative anomalies. The changes in surface and upper ocean temperatures take about $1-2 \mathrm{yr}$ before the ocean LW outgoing radiation is rebalanced with solar irradiance anomalies. Another possible mechanism is that peak solar irradiance can lead to stratospheric heating, and then poleward and downward displacements in wind anomalies in the stratosphere and troposphere (Haigh 1996). Furthermore, in the 1-2 yr following tropical volcanic eruptions, significant changes of surface temperature have occurred (Santer et al. 2001; D'Arrigo et al. 2009). These observations can partly support the lag-lead correlations in the CMIP5 models and may be helpful in understanding the corresponding physical mechanisms. Given the primary roles of tropical air-sea interactions in climate system, SST anomalies in tropics are more easily amplified than those in the extratropics, and then the former can force the decadal variability of global SAT (Lau 1997; Alexander et al. 2002). These may provide an explanation for the consistent lag months between TOA SW fluxes and SAT as shown in Fig. 5.

The most recent studies (Meehl and Teng 2012, 2014; Guemas et al. 2013) have shown that the initialized decadal hindcasts produced a more realistic early 2000 s hiatus than uninitialized climate projection experiments. Using a global climate model that factored in the observed EEP SST, Kosaka and Xie (2013) offered an explanation for the recent hiatus. However, none of the recent literature has directly addressed the questions of whether the EEP SST anomalies or initial climate conditions came from external forcing or internal variability. Meehl et al. (2009) showed that increased GHG concentrations could produce a positive phase of the IPO, as in the mid-1970s climate shift. However, our studies have shown the significant modulations of external forcing, especially natural forcing, that may contribute to the warming hiatus. The possible causes of the recent global warming hiatus include a slowdown in TOA radiate forcing due to a low solar minimum (Hansen et al. 2011), changes in stratospheric water vapor (Solomon et al. 2010), volcanic aerosols (Santer et al. 2014, 2015), and anthropogenic aerosols (Kaufmann et al. 2011; Estrada et al. 2013). Almost all CMIP5 historical simulations 
have overestimated global warming over the past 20 years (Fyfe et al. 2013a,b; Santer et al. 2014). But through updating the external forcings (including volcanic aerosols, solar irradiances, and human-made aerosols) and adjusting internal variability (e.g., ENSO), the recent hiatus in CMIP5 models and observations has been almost completely reconciled (Schmidt et al. 2014). Therefore, in combination with these present studies, external forcing cannot be ignored when discussing the decadal variability of SAT. Identifying its roles will provide an opportunity to narrow the uncertainty in climate predictions of the coming decades.

Acknowledgments. We would like to thank the two anonymous reviewers for their comments, which were very helpful in improving the manuscript. This study is jointly supported by the National Key Program for Developing Basic Sciences (Grant 2013CB956204) and the "Strategic Priority Research Program Climate Change: Carbon Budget and Relevant Issues" of the Chinese Academy of Sciences (Grant XDA05110302).

\section{REFERENCES}

Alexander, M. A., I. Bladé, M. Newman, J. R. Lanzante, N.-C. Lau, and J. D. Scott, 2002: The atmospheric bridge: The influence of ENSO teleconnections on air-sea interaction over the global oceans. J. Climate, 15, 2205-2231, doi:10.1175/1520-0442(2002)015<2205: $\mathrm{TABTIO}>2.0 . \mathrm{CO} ; 2$.

Ammann, C. M., G. A. Meehl, W. M. Washington, and C. S. Zender, 2003: A monthly and latitudinally varying volcanic forcing dataset in simulations of 20th century climate. Geophys. Res. Lett., 30, 1657, doi:10.1029/2003GL016875.

Bellenger, H., E. Guilyardi, J. Leloup, M. Lengaigne, and J. Vialard, 2014: ENSO representation in climate models: From CMIP3 to CMIP5. Climate Dyn., 42, 1999-2018, doi:10.1007/ s00382-013-1783-z.

Bretherton, C. S., M. Widmann, V. P. Dymnikov, J. M. Wallace, and I. Bladé, 1999: The effective number of spatial degrees of freedom of a time-varying field. J. Climate, 12, 1990-2009, doi:10.1175/1520-0442(1999)012<1990:TENOSD>2.0.CO;2.

Cui, X., Y. Gao, J. Sun, D. Guo, S. Li, and O. M. Johannessen, 2014 Role of natural external forcing factors in modulating the Indian summer monsoon rainfall, the winter North Atlantic Oscillation and their relationship on inter-decadal timescale. Climate Dyn., 43, 2283-2295, doi:10.1007/s00382-014-2053-4.

D'Arrigo, R., R. Wilson, and A. Tudhope, 2009: The impact of volcanic forcing on tropical temperatures during the past four centuries. Nat. Geosci., 2, 51-56, doi:10.1038/ngeo393.

Delworth, T., and R. J. Greatbatch, 2000: Multidecadal thermohaline circulation variability driven by atmospheric surface flux forcing. J. Climate, 13, 1481-1495, doi:10.1175/1520-0442(2000)013<1481: MTCVDB $>2.0 . C O ; 2$.

_, S. Manabe, and R. J. Stouffer, 1993: Interdecadal variations of the thermohaline circulation in a coupled ocean-atmosphere model J. Climate, 6, 1993-2011, doi:10.1175/1520-0442(1993)006<1993: IVOTTC $>2.0 . \mathrm{CO} ; 2$.

Dong, L., T. Zhou, and X. Chen, 2014: Changes of Pacific decadal variability in the twentieth century driven by internal variability, greenhouse gases, and aerosols. Geophys. Res. Lett., 41, 8570 8577, doi:10.1002/2014GL062269.
Driscoll, S., A. Bozzo, L. J. Gray, A. Robock, and G. Stenchikov, 2012: Coupled Model Intercomparison Project 5 (CMIP5) simulations of climate following volcanic eruptions. J. Geophys. Res., 117, D17105, doi:10.1029/2012JD017607.

Duvel, J. P., R. Roca, and J. Vialard, 2004: Ocean mixed layer temperature variations induced by intraseasonal convective perturbations over the Indian Ocean. J. Atmos. Sci., 61, 1004-1023, doi:10.1175/1520-0469(2004)061<1004:OMLTVI>2.0.CO;2.

Easterling, D. R., and M. F. Wehner, 2009: Is the climate warming or cooling? Geophys. Res. Lett., 36, L08706, doi:10.1029/ 2009GL037810.

Eden, C., and T. Jung, 2001: North Atlantic interdecadal variability: Oceanic response to the North Atlantic Oscillation (1865-1997). J. Climate, 14, 676-691, doi:10.1175/1520-0442(2001)014<0676: NAIVOR $>2.0 . \mathrm{CO} ; 2$

England, M. H., and Coauthors, 2014: Recent intensification of wind-driven circulation in the Pacific and the ongoing warming hiatus. Nat. Climate Change, 4, 222-227, doi:10.1038/ nclimate2106.

Estrada, F., P. Perron, and B. Martínez-López, 2013: Statistically derived contributions of diverse human influences to twentieth-century temperature changes. Nat. Geosci., 6, 10501055, doi:10.1038/ngeo1999.

Flato, G., and Coauthors, 2014: Evaluation of climate models. Climate Change 2013: The Physical Science Basis, T. F. Stocker et al., Eds., Cambridge University Press, 741-866.

Fyfe, J. C., N. P. Gillett, and F. W. Zwiers, 2013a: Overestimated global warming over the past 20 years. Nat. Climate Change, $\mathbf{3}$, 767-769, doi:10.1038/nclimate1972.

_, K. von Salzen, J. N. S. Cole, N. P. Gillett, and J.-P. Vernier, 2013b: Surface response to stratospheric aerosol changes in a coupled atmosphere-ocean model. Geophys. Res. Lett., 40, 584-588, doi:10.1002/grl.50156.

Gillett, N. P., F. W. Zwiers, A. J. Weaver, G. C. Hegerl, M. R. Allen, and P. A. Stott, 2002: Detecting anthropogenic influence with a multi-model ensemble. Geophys. Res. Lett., 29, 1970, doi:10.1029/2002GL015836.

Guemas, V., F. J. Doblas-Reyes, I. Andreu-Burillo, and M. Asif, 2013: Retrospective prediction of the global warming slowdown in the past decade. Nat. Climate Change, 3, 649-653, doi:10.1038/nclimate1863.

Haigh, J. D., 1996: The impact of solar variability on climate. Science, 272, 981-984, doi:10.1126/science.272.5264.981.

Hansen, J., M. Sato, P. Kharecha, and K. von Schuckmann, 2011: Earth's energy imbalance and implications. Atmos. Chem. Phys., 11, 13 421-13 449, doi:10.5194/acp-11-13421-2011.

Ineson, S., A. A. Scaife, J. R. Knight, J. C. Manners, N. J. Dunstone, L. J. Gray, J. D. Haigh, 2011: Solar forcing of winter climate variability in the Northern Hemisphere. Nat. Geosci., 4, 753757, doi:10.1038/ngeo1282.

Jin, F.-F., 1997: A theory of interdecadal climate variability of the North Pacific ocean-atmosphere system. J. Climate, 10, 1821-1835, doi:10.1175/1520-0442(1997)010<1821:ATOICV > 2.0.CO;2.

Kaufmann, R. E., H. Kauppi, M. L. Mann, and J. H. Stock, 2011: Reconciling anthropogenic climate change with observed temperature 1998-2008. Proc. Natl. Acad. Sci. USA, 108, 1179011 793, doi:10.1073/pnas.1102467108.

Kim, S. T., and J.-Y. Yu, 2012: The two types of ENSO in CMIP5 models. Geophys. Res. Lett., 39, L11704, doi:10.1029/2012GL052006.

Knutson, T. R., and S. Manabe, 1995: Time-mean response over the tropical Pacific to increased $\mathrm{CO}_{2}$ in a coupled oceanatmosphere model. J. Climate, 8, 2181-2199, doi:10.1175/ 1520-0442(1995)008<2181:TMROTT>2.0.CO;2. 
Kosaka, Y., and S.-P. Xie, 2013: Recent global-warming hiatus tied to equatorial Pacific surface cooling. Nature, 501, 403-407, doi:10.1038/nature12534.

Lambert, S. J., and G. J. Boer, 2001: CMIP1 evaluation and intercomparison of coupled climate models. Climate Dyn., 17, 83-106, doi:10.1007/PL00013736.

Langenbrunner, B., and J. D. Neelin, 2013: Analyzing ENSO teleconnections in CMIP models as a measure of model fidelity in simulating precipitation. J. Climate, 26, 4431-4446, doi:10.1175/ JCLI-D-12-00542.1.

Latif, M., and T. P. Barnett, 1995: Interactions of the tropical oceans. J. Climate, 8, 952-964, doi:10.1175/1520-0442(1995)008<0952: IOTTO $>2.0 . \mathrm{CO} ; 2$.

Lau, N. C., 1997: Interactions between global SST anomalies and the midlatitude atmospheric circulation. Bull. Amer. Meteor. Soc., 78, 21-33, doi:10.1175/1520-0477(1997)078<0021: IBGSAA $>2.0 . \mathrm{CO} ; 2$

Li, J., C. Sun, and F.-F. Jin, 2013: NAO implicated as a predictor of Northern Hemisphere mean temperature multidecadal variability. Geophys. Res. Lett., 40, 5497-5502, doi:10.1002/ 2013 GL057877.

Liu, J., B. Wang, M. A. Cane, S.-Y. Yim, and J.-Y. Lee, 2013: Divergent global precipitation changes induced by natural versus anthropogenic forcing. Nature, 493, 656-659, doi:10.1038/ nature11784.

Liu, Z., S. Vavrus, F. He, N. Wen, and Y. Zhong, 2005: Rethinking tropical ocean response to global warming: The enhanced equatorial warming. J. Climate, 18, 4684-4700, doi:10.1175/ JCLI3579.1.

Luo, J.-J., W. Sasaki, and Y. Masumoto, 2012: Indian Ocean warming modulates Pacific climate change. Proc. Natl. Acad. Sci. USA, 109, 18 701-18706, doi:10.1073/pnas.1210239109.

Luo, Y., J. Lu, F. Liu, and W. Liu, 2015: Understanding the El Niñolike oceanic response in the tropical Pacific to global warming. Climate Dyn., doi:10.1007/s00382-014-2448-2, in press.

Mantua, N. J., S. R. Hare, Y. Zhang, J. M. Wallace, and R. C. Francis, 1997: A Pacific interdecadal climate oscillation with impacts on salmon production. Bull. Amer. Meteor. Soc., 78, 1069-1079, doi:10.1175/1520-0477(1997)078<1069:APICOW>2.0.CO;2.

McGregor, S., A. Timmermann, M. F. Stuecker, M. H. England, M. Merrifield, F.-F. Jin, and Y. Chikamoto, 2014: Recent Walker circulation strengthening and Pacific cooling amplified by Atlantic warming. Nat. Climate Change, 4, 888-892, doi:10.1038/ nclimate2330.

Meehl, G. A., and W. M. Washington, 1996: El Niño-like climate change in a model with increased atmospheric $\mathrm{CO}_{2}$ concentrations. Nature, 382, 56-60, doi:10.1038/382056a0.

_ Australian monsoon-ENSO-TBO relationships. J. Climate, 24, 4925-4940, doi:10.1175/2011JCLI4015.1.

— hindcasts and predictions for the Pacific region. Geophys. Res. Lett., 39, L22705, doi:10.1029/2012GL053423.

— , and - 2014: CMIP5 multi-model hindcasts for the mid1970s shift and early 2000s hiatus and predictions for 2016-2035. Geophys. Res. Lett., 41, 1711-1716, doi:10.1002/2014GL059256.

$\longrightarrow$, A. Hu, and B. D. Santer, 2009: The mid-1970s climate shift in the Pacific and the relative roles of forced versus inherent decadal variability. J. Climate, 22, 780-792, doi:10.1175/2008JCLI2552.1.

_ J. M. Arblaster, J. T. Fasullo, A. Hu, and K. Trenberth, 2011: Model-based evidence of deep-ocean heat uptake during surface-temperature hiatus periods. Nat. Climate Change, 1, 360-364, doi:10.1038/nclimate1229.
— A. Hu, J. M. Arblaster, J. Fasullo, and K. Trenberth, 2013: Externally forced and internally generated decadal climate variability associated with the interdecadal Pacific oscillation. J. Climate, 26, 7298-7310, doi:10.1175/JCLI-D-12-00548.1.

Ohba, M., H. Shiogama, T. Yokohata, and M. Watanabe, 2013: Impact of strong tropical volcanic eruptions on ENSO simulated in a coupled GCM. J. Climate, 26, 5169-5182, doi:10.1175/ JCLI-D-12-00471.1.

Otterå, O. H., M. Bentsen, H. Drange, and L. Suo, 2010: External forcing as a metronome for Atlantic multidecadal variability. Nat. Geosci., 3, 688-694, doi:10.1038/ngeo955.

Palmer, M. D., D. J. McNeall, and N. J. Dunstone, 2011: Importance of the deep ocean for estimating decadal changes in Earth's radiation balance. Geophys. Res. Lett., 38, L13707, doi:10.1029/2011GL047835.

Parker, D., C. Folland, A. Scaife, J. Knight, A. Colman, P. Baines, and B. Dong, 2007: Decadal to multidecadal variability and the climate change background. J. Geophys. Res., 112, D18115, doi:10.1029/2007JD008411.

Power, S., T. Casey, C. Folland, A. Colman, and V. Mehta, 1999: Inter-decadal modulation of the impact of ENSO on Australia. Climate Dyn., 15, 319-324, doi:10.1007/s003820050284.

Santer, B. D., and Coauthors, 2001: Accounting for the effects of volcanoes and ENSO in comparisons of modeled and observed temperature trends. J. Geophys. Res., 106, 28033-28059, doi:10.1029/2000JD000189.

- and Coauthors, 2014: Volcanic contribution to decadal changes in tropospheric temperature. Nat. Geosci., 7, 185-189, doi:10.1038/ngeo2098.

_ , and Coauthors, 2015: Observed multivariable signals of late 20th and early 21 st century volcanic activity. Geophys. Res. Lett., 42, 500-509, doi:10.1002/2014GL062366.

Sato, M., J. Hansen, M. McCormick, and J. Pollack, 1993: Stratospheric aerosol optical depths, 1850-1990. J. Geophys. Res., 98, 22 987-22 994, doi:10.1029/93JD02553.

Schmidt, G. A., D. T. Shindell, and K. Tsigaridis, 2014: Reconciling warming trends. Nat. Geosci., 7, 158-160, doi:10.1038/ngeo2105.

Shindell, D. T., G. A. Schmidt, M. E. Mann, D. Rind, and A. Waple, 2001: Solar forcing of regional climate change during the Maunder Minimum. Science, 294, 2149-2152, doi:10.1126/science.1064363.

Solomon, S., K. H. Rosenlof, R. W. Portmann, J. S. Daniel, S. M. Davis, T. J. Sanford, and G.-K. Plattner, 2010: Contributions of stratospheric water vapor to decadal changes in the rate of global warming. Science, 327, 1219-1223, doi:10.1126/science.1182488.

Song, Y., Y. Q. Yu, and P. F. Lin, 2014: The hiatus and accelerated warming decades in CMIP5 simulations. Adv. Atmos. Sci., 31, 1316-1330, doi:10.1007/s00376-014-3265-6.

Stenchikov, G., K. Hamilton, R. J. Stouffer, A. Robock, V. Ramaswamy, B. Santer, and H.-F. Graf, 2006: Arctic Oscillation response to volcanic eruptions in the IPCC AR4 climate models. J. Geophys. Res., 111, D07107, doi:10.1029/2005JD006286.

Trenberth, K. E., and J. W. Hurrell, 1994: Decadal atmosphereocean variations in the Pacific. Climate Dyn., 9, 303-319, doi:10.1007/BF00204745.

Tung, K.-K., and J. Zhou, 2013: Using data to attribute episodes of warming and cooling in instrumental records. Proc. Natl. Acad. Sci. USA, 110, 2058-2063, doi:10.1073/pnas.1212471110.

Vialard, J., and Coauthors, 2009a: Cirene: Air-sea interactions in the Seychelles-Chagos thermocline ridge region. Bull. Amer. Meteor. Soc., 90, 45-61, doi:10.1175/2008BAMS2499.1.

, S. S. C. Shenoi, J. P. McCreary, D. Shankar, F. Durand, V. Fernando, and S. R. Shetye, 2009b: Intraseasonal response 
of the northern Indian Ocean coastal waveguide to the Madden-Julian oscillation. Geophys. Res. Lett., 36, L14606, doi:10.1029/2009GL038450.

Visbeck, M., H. Cullen, G. Krahmann, and N. Naik, 1998: An ocean model's response to North Atlantic Oscillation-like wind forcing. Geophys. Res. Lett., 25, 4521-4524, doi:10.1029/1998GL900162.

Wang, T., O. H. Otterå, Y. Gao, and H. Wang, 2012: The response of the North Pacific decadal variability to strong tropical volcanic eruptions. Climate Dyn., 39, 2917-2936, doi:10.1007/s00382-012-1373-5.

White, W. B., J. Lean, D. R. Cayan, and M. D. Dettinger, 1997: Response of global upper ocean temperature to changing solar irradiance. J. Geophys. Res., 102, 3255-3266, doi:10.1029/96JC03549.
Xie, S.-P., C. Deser, G. A. Vecchi, J. Ma, H. Teng, and A. T. Wittenberg, 2010: Global warming pattern formation: Sea surface temperature and rainfall. J. Climate, 23, 966-986, doi:10.1175/2009JCLI3329.1.

Yu, B., and G. J. Boer, 2002: The roles of radiation and dynamical processes in the El Niño-like response to global warming. Climate Dyn., 19, 539-554, doi:10.1007/s00382-002-0244-x.

Zanchettin, D., C. Timmreck, H.-F. Graf, A. Rubino, S. Lorenz, K. Lohmann, K. Krüger, and J. H. Jungclaus, 2012: Bi-decadal variability excited in the coupled ocean-atmosphere system by strong tropical volcanic eruptions. Climate Dyn., 39, 419-444, doi:10.1007/s00382-011-1167-1. 